\section{Acesso ao exame citológico do colo do útero em região de saúde: mulheres invisíveis e corpos vulneráveis}

\author{
Access to uterine cervical cytology in a \\ health region: invisible women and \\ vulnerable bodies
}

\author{
Noêmia Fernanda Santos Fernandes 1 \\ Jôse Ribas Galvão 1 \\ Marluce Maria Araújo Assis 2 \\ Patty Fidelis de Almeida 3 \\ Adriano Maia dos Santos 1
}

\section{Resumo}

Este artigo avalia o acesso ao exame Papanicolaou na Estratégia Saúde da Família (ESF), em municípios de uma região de saúde. O controle do câncer do colo do útero depende de uma ESF organizada, portanto, avaliar o acesso ao teste de Papanicolaou revela a qualidade da assistência neste nível de atenção. Trata-se de estudo qualitativo, com dados produzidos em 10 grupos focais, perfazendo 70 participantes, em quatro municípios. Analisaram-se as dimensões organizacional, simbólica e técnica do acesso ao exame preventivo, tendo como condição marcadora o câncer do colo do útero. Os resultados indicaram que residir em zona rural era barreira para o acesso ao exame Papanicolaou e reforçavam as iniquidades. Enfermeiros eram a principal referência para a realização do exame preventivo. A ausência de itens necessários à coleta de material citopatológico foi uma barreira de acesso em todos os municípios. Havia entraves de acesso às mulheres com alguma deficiência e às mulheres lésbicas, com atendimento fragmentado e descontextualizado das singularidades pessoais. Os inúmeros entraves de acesso ao Papanicolaou expuseram a seletividade da ESF na região de saúde, visto que reproduzia a invisibilidade das mulheres com maior vulnerabilidade social e acentuava as desigualdades.

Acesso aos Serviços de Saúde; Neoplasias do Colo de Útero; Saúde da População Rural; Atenção Primária à Saúde; Saúde da Mulher

\author{
Correspondência \\ A. M. Santos \\ Instituto Multidisciplinar em Saúde, Universidade Federal da \\ Bahia. \\ Rua Hormindo Barros 58, Quadra 17, Lote 58, Vitória da \\ Conquista, BA 45.029-094, Brasil. \\ maiaufba@ufba.br \\ 1 Universidade Federal da Bahia, Vitória da Conquista, Brasil. \\ 2 Universidade Estadual de Feira de Santana, Feira de Santana, \\ Brasil. \\ 3 Universidade Federal Fluminense, Niterói, Brasil.
}




\section{Introdução}

O acesso ao sistema de serviço de saúde configura um dispositivo para a produção do cuidado, por ser condição para que os fluxos assistenciais sejam operacionalizados pelos profissionais ${ }^{1}$. Dessa forma, é no espaço intercessor entre trabalhador de saúde e usuário que o acesso se materializa, desencadeado pelo olhar atento, pela atuação acolhedora e pelo vínculo construído na intersubjetividade do encontro, ou seja, o acesso não se resume à entrada do usuário nos serviços, mas se conforma frente à micropolítica do trabalho em saúde 2 .

O conceito de acesso à saúde é, portanto, complexo e se apresenta de forma multifacetada e multidimensional, com aspectos de difícil mensuração 3,4. Desse modo, as diversas variáveis que possam impedir o usuário de alcançar um direito que lhe é garantido formalmente devem ser consideradas, isto é, quaisquer barreiras - política, econômico-social, organizacional, técnica ou simbólica - à universalidade e à integralidade do acesso à saúde devem ser avaliadas e compreendidas 5 . Além disso, melhorar o acesso aos serviços para populações vulneráveis com vistas a atingir a equidade constitui um desafio ainda maior $6,7,8$.

A experiência de alguns países com sistemas de saúde integrados mostra que a incidência de câncer do colo do útero pode ser reduzida em torno de $80 \%$ onde o rastreamento citológico for implantado com qualidade, acompanhado pelo seguimento adequado e oportuno das mulheres, e de um bom sistema de comunicação entre os serviços de saúde e as usuárias, o que depende da articulação de toda a rede de cuidados 9,10 .

Entretanto, mesmo em cenários com oferta regular de rastreamento do câncer do colo do útero não tem havido uma diminuição expressiva em sua incidência, em decorrência da sinergia de fatores como conhecimento e representações das mulheres sobre a doença 11,12 - programas de rastreamento predominantemente oportunistas 9,13 , baixa condição socioeconômica 14,15 , qualidade do rastreamento 16 , atraso no diagnóstico e no início do tratamento 17,18, além da estrutura e do processo de trabalho das equipes 19. Desse modo, é evidente a necessidade de aliar as dimensões organizativas, técnicas e simbólicas do acesso para a implantação exitosa das políticas de prevenção e controle do câncer do colo do útero.

Embora seja elevada a incidência de câncer do colo do útero no Brasil, também é reconhecido que a mortalidade por esta neoplasia é evitável, considerando-se que as ações para seu controle contam com tecnologias para o diagnóstico e tratamento de lesões precursoras, o que permite a cura em aproximadamente $100 \%$ dos casos diagnosticados na fase inicial 9 . Entre as estratégias eficazes para a deteç̧ão precoce do câncer do colo do útero estão os programas organizados de rastreamento que dependem, no caso brasileiro, de ampla cobertura e organização da atenção primária à saúde (APS), tanto para a captação das mulheres, quanto para a realização do exame citopatológico do colo do útero, método amplamente utilizado para a detecção das lesões precursoras 9,10.

O câncer do colo do útero é um marcador pertinente para a compreensão dos fluxos assistenciais na rede de cuidados que vão da APS aos serviços especializados 20. Outrossim, o controle do câncer do colo do útero depende de uma APS organizada, portanto, avaliar o acesso ao teste de Papanicolaou revela a qualidade da assistência neste nível da Rede de Atenção à Saúde (RAS).

No caso do câncer do colo do útero, além da captação e realização do exame citopatológico, cabe às equipes de APS o encaminhamento das mulheres que necessitam de confirmação diagnóstica e tratamento das lesões precursoras para unidades de atenção especializada e o acompanhamento longitudinal, mesmo quando a usuária se encontra em outros níveis de atenção na região de saúde 9,18. Para tal, deve-se conhecer e mapear nos territórios sanitários, sob a responsabilidade da APS, as possíveis barreiras de acesso ao exame cervicouterino, sobretudo, para identificar as mulheres invisíveis e vulneráveis 6,17 .

Assim, entende-se que a APS deveria ser o centro de comunicação da RAS e nó intercambiador no qual se coordenam os fluxos e os contrafluxos 21,22. Por sua vez, a centralidade na APS exige, também, acolhimento dos usuários com ambiência adequada e que os profissionais consigam abarcar diferentes demandas, inclusive a demanda espontânea, estabelecendo prioridades (urgência, vulnerabilidade social, condição de saúde) de forma balanceada 23 .

Nessa perspectiva, este artigo avalia o acesso ao exame citológico do câncer do útero na Estratégia Saúde da Família (ESF), em municípios de uma região de saúde da Bahia. 


\section{Metodologia}

Trata-se de estudo de caso, com abordagem qualitativa 24, na região de saúde de Vitória da Conquista, Bahia. Uma região de saúde é definida como o espaço geográfico constituído por agrupamentos de municípios limítrofes, com a finalidade de integrar a organização, o planejamento e a execução de ações e serviços de saúde 25 .

Os 19 municípios que compõem a região de saúde (Tabela 1) foram agrupados em estratos por contingente populacional: Estrato 1 - até 20 mil habitantes; Estrato 2 - entre 20.001 e 50 mil; Estrato 3 - mais que 50 mil.

Foram eleitos quatro municípios (dos diferentes estratos populacionais) para ilustrar a diversidade na organização da ESF e as barreiras de acesso às unidades de saúde da família (USF), numa região de saúde. O critério de seleção dos municípios foi realizado pelo cruzamento de informações consideradas relevantes durante a exploração do campo 24: (a) indicação de informantes-chave; (b) observação em seis reuniões da Comissão Intergestores Regional; (c) cobertura da ESF: > 90\%; (d) municípios de porte populacional distinto; (e) diferentes tipos de gestão de saúde - em Comando Único ou Gestão Estadual; (f) inclusão do município sede da região de saúde - independentemente da cobertura da ESF (Tabela 1).

Como instrumento analítico foi construída uma "matriz de análise do acesso" (Quadro 1), por meio de três dimensões: organizacional, simbólica e técnica 5. A dimensão organizacional abarca aspectos relacionados à infraestrutura e aos insumos, tais como: frequência e local da oferta dos serviços; forma de marcação; meio de locomoção à unidade de saúde e prática profissional. A dimensão simbólica abrange aspectos atitudinais (estigmas e estereótipos); acolhimento e vínculo; bagagem cultural e crenças; percepção/expectativas dos usuários; além dos valores pessoais e sociais dos usuários. A dimensão técnica, por sua vez, compreende a competência dos profissionais para lidar com o processo saúde/doença nas perspectivas individual e coletiva. Todas as dimensões foram interpretadas pela óptica de enfermeiros e agentes comunitários de saúde (ACS).

Elegeram-se profissionais da ESF com atuação cotidiana na linha de cuidado do CCU. Os critérios de inclusão foram: (1) enfermeiros indicados pelo gestor municipal; (2) ACS apontados pelos enfermeiros selecionados; (3) profissionais (ACS e enfermeiros) de diferentes USF; e (4) profissionais com maior tempo de experiência na ESF.

Os resultados emergiram de análises e cruzamentos de dados produzidos em 10 grupos focais (GF) 24,26,27. Realizaram-se cinco GF com enfermeiros (GF-E) e cinco GF com ACS (GF-A), perfazendo 70 participantes. Para a composição, foram realizados dois GF (com ACS e outro com enfermeiros) por município (Maetinga, Barra do Choça e Poções), mesclando profissionais das zonas rural e urbana. No Município de Vitória da Conquista, em decorrência do maior número de equipes, realizaramse quatro GF, sendo dois grupos com ACS e dois com enfermeiros (Quadro 2).

A intenção não foi o julgamento de cada município isoladamente, mas a compreensão de processos que acontecem no território regional, por meio de cenários representativos, analisando-se as dimensões organizacional, simbólica e técnica do acesso ao Papanicolaou, tendo como condição marcadora 20 o câncer do colo do útero. Além disso, os quatro municípios juntos somam mais de $60 \%$ da população da região de saúde, constituindo, por conseguinte, um corpus (universo estudado) representativo dos fenômenos regionais, pois contêm as características essenciais do universo pretendido 24 .

Para a interpretação dos resultados, realizou-se a ordenação dos dados 24 com base na leitura geral do material transcrito e na primeira organização dos dados contemplados nos dez grupos focais. $\mathrm{O}$ material foi ordenado e classificado, etapas em que as transcrições foram lidas exaustivamente e os núcleos temáticos foram selecionados, agrupados e categorizados. Foram confrontados os argumentos dos GF e, em seguida, partiu-se para o cotejamento entre os discursos, no confronto dialético de ideias e posições dos sujeitos. Para a análise final dos dados 24 , fez-se o entrecruzamento das informações coletadas, identificando-se as convergências e divergências para a produção de interpretação compreensiva e crítica.

A pesquisa foi aprovada pelo Comitê de Ética em Pesquisa da Universidade Federal da Bahia (Parecer no 624.168). 
Tabela 1

Caracterização dos municípios, cobertura pela Estratégia Saúde da Família (ESF) e número de equipes de saúde da família. Região de Saúde de Vitória da Conquista, Bahia, Brasil, 2018.

\begin{tabular}{|c|c|c|c|c|c|c|c|}
\hline Município & $\begin{array}{c}\text { População } \\
\text { (2010) }\end{array}$ & $\begin{array}{c}\text { População } \\
\text { estimada * } \\
\text { (2018) }\end{array}$ & $\begin{array}{c}\text { População da } \\
\text { zona rural * } \\
\text { (2010) }\end{array}$ & $\begin{array}{c}\text { Taxa de } \\
\text { urbanização * } \\
(2010)[\%]\end{array}$ & $\begin{array}{l}\text { IDHM ** } \\
(2010)\end{array}$ & $\begin{array}{l}\text { Cobertura } \\
\text { ESF *** } \\
(2017)[\%]\end{array}$ & $\begin{array}{c}\text { Número } \\
\text { de EqSF \# } \\
\text { (2017) }\end{array}$ \\
\hline \multicolumn{8}{|l|}{ Estrato 1} \\
\hline \multirow[t]{2}{*}{ Maetinga } & 7.038 & 3.577 & 4.221 & 40 & 0,538 & 100 & $\mathrm{ZU}-1$ \\
\hline & & & & & & & $Z R-4$ \\
\hline \multirow[t]{2}{*}{ Cordeiros } & 8.168 & 8.585 & 5.617 & 31 & 0,579 & 100 & $Z U-3$ \\
\hline & & & & & & & $Z R-2$ \\
\hline \multirow[t]{2}{*}{ Ribeirão do Largo } & 8.602 & 6.304 & 3.955 & 54 & 0,540 & 100 & $Z U-1$ \\
\hline & & & & & & & $Z R-3$ \\
\hline \multirow[t]{2}{*}{ Bom Jesus da Serra } & 10.113 & 9.942 & 7.345 & 27 & 0,546 & 100 & $Z U-2$ \\
\hline & & & & & & & $Z R-2$ \\
\hline \multirow[t]{2}{*}{ Caraíbas } & 10.222 & 9.107 & 7.709 & 24 & 0,555 & 100 & $\mathrm{ZU}-1$ \\
\hline & & & & & & & $Z R-3$ \\
\hline \multirow[t]{2}{*}{ Mirante } & 10.507 & 8.844 & 8.698 & 17 & 0,665 & 100 & $\mathrm{ZU}-1$ \\
\hline & & & & & & & $Z R-4$ \\
\hline \multirow[t]{2}{*}{ Piripá } & 12.783 & 10.952 & 6.588 & 48 & 0,575 & 100 & $Z U-2$ \\
\hline & & & & & & & $Z R-4$ \\
\hline \multirow[t]{2}{*}{ Caetanos } & 13.639 & 15.524 & 10.348 & 24 & 0,542 & 100 & $Z U-3$ \\
\hline & & & & & & & $Z R-5$ \\
\hline \multirow[t]{2}{*}{ Presidente Jânio Quadros } & 13.652 & 12.505 & 9.454 & 30 & 0,542 & 100 & $Z U-4$ \\
\hline & & & & & & & $Z R-4$ \\
\hline \multirow[t]{2}{*}{ Belo Campo } & 16.021 & 17.317 & 6.992 & 56 & 0,575 & 100 & $Z U-3$ \\
\hline & & & & & & & $Z R-3$ \\
\hline \multirow[t]{2}{*}{ Condeúba } & 16.898 & 17.319 & 9.436 & 44 & 0,582 & 100 & $Z U-3$ \\
\hline & & & & & & & $Z R-5$ \\
\hline \multirow[t]{2}{*}{ Tremedal } & 17.029 & 16.608 & 6.636 & 23 & 0,528 & 100 & $Z U-3$ \\
\hline & & & & & & & $Z R-4$ \\
\hline \multicolumn{8}{|l|}{ Estrato 2} \\
\hline \multirow[t]{2}{*}{ Encruzilhada } & 23.766 & 17.593 & 18.636 & 21 & 0,544 & 100 & $\mathrm{ZU}-2$ \\
\hline & & & & & & & $Z R-5$ \\
\hline \multirow[t]{2}{*}{ Planalto } & 24.481 & 26.092 & 9.612 & 60 & 0,560 & 100 & $Z U-3$ \\
\hline & & & & & & & $Z R-6$ \\
\hline \multirow[t]{2}{*}{ Anagé } & 25.516 & 18.194 & 20.592 & 67 & 0,540 & 100 & $Z U-3$ \\
\hline & & & & & & & $Z R-8$ \\
\hline \multirow[t]{2}{*}{ Cândido Sales } & 27.918 & 25.332 & 8.632 & 69 & 0,601 & 100 & $Z U-6$ \\
\hline & & & & & & & $Z R-3$ \\
\hline \multirow[t]{2}{*}{ Barra do Choça } & 34.788 & 32.018 & 12.381 & 64 & 0,551 & 100 & $Z U-6$ \\
\hline & & & & & & & $Z R-6$ \\
\hline \multirow[t]{2}{*}{ Poções } & 44.701 & 46.862 & 10.042 & 77 & 0,604 & 100 & $\mathrm{ZU}-11$ \\
\hline & & & & & & & $Z R-4$ \\
\hline \multicolumn{8}{|l|}{ Estrato 3} \\
\hline \multirow[t]{2}{*}{ Vitória da Conquista } & 306.866 & 338.885 & 32.127 & 89 & 0,678 & 45 & $Z U-26$ \\
\hline & & & & & & & $Z R-18$ \\
\hline
\end{tabular}

EqSF: equipe de saúde da família; IDHM: Índice de Desenvolvimento Humano Municipal; ZR: zona rural; ZU: zona urbana.

Fontes: * Instituto Brasileiro de Geografia e Estatística. https://cidades.ibge.gov.br/ (acessado em 20/Set/2018); ** Atlas do Desenvolvimento Humano no Brasil, 2013. http://atlasbrasil.org.br/2013/ (acessado em 20/Set/2018); *** Ministério da Saúde. e-Gestor atenção básica - informação e gestão da atenção básica, 2017. https://egestorab.saude.gov.br/paginas/acessoPublico/relatorios/relHistoricoCoberturaAB.xhtml (acessado em 20/Set/2018);

\# Secretaria da Saúde do Estado da Bahia. Núcleo Regional de Saúde, 2018. 


\section{Quadro 1}

Dimensões de análise do acesso.

\begin{tabular}{|c|c|c|}
\hline $\begin{array}{l}\text { Dimensões do } \\
\text { acesso }\end{array}$ & Tema de análise & Categorias empíricas \\
\hline \multirow{8}{*}{$\begin{array}{l}\text { Dimensão } \\
\text { organizacional }\end{array}$} & Tipo de oferta de preventivo & \multirow{8}{*}{$\begin{array}{c}\text { Desafios da mulher do campo e táticas } \\
\text { profissionais }\end{array}$} \\
\hline & Local da oferta do preventivo & \\
\hline & Frequência na oferta de preventivo & \\
\hline & Forma de marcação para exame preventivo & \\
\hline & Meio de locomoção à unidade de saúde & \\
\hline & Profissional que faz o exame de Papanicolaou & \\
\hline & Processo de trabalho do ACS & \\
\hline & Infraestrutura e insumos para coleta de preventivo & \\
\hline \multirow{4}{*}{$\begin{array}{l}\text { Dimensão } \\
\text { simbólica }\end{array}$} & Mulheres com deficiência & \multirow{5}{*}{ Intersubjetividade e a produção do cuidado } \\
\hline & Orientação sexual das usuárias & \\
\hline & Acolhimento e vínculo & \\
\hline & Valores pessoais e sociais & \\
\hline Dimensão técnica & Competência técnica da equipe & \\
\hline
\end{tabular}

ACS: agentes comunitários de saúde.

\section{Resultados e discussão}

Os resultados (Quadros 3 e 4) e discussão foram agrupados em duas categorias empíricas: Dimensão Organizacional do Acesso: Desafios da Mulher do Campo e Táticas Profissionais e Dimensões Simbólica e Técnica do Acesso: Intersubjetividade e a Produção do Cuidado. Além disso, para cada categoria, foram destacados os temas que serviram de fio condutor dos grupos focais.

\section{Dimensão organizacional do acesso: desafios da mulher do campo e táticas profissionais}

\section{- Temas: tipo, local e frequência de oferta, forma de marcação do exame e meio de locomoção da mulher para acesso ao preventivo}

Entre as práticas assistenciais 23, conforme os GF, todas as USF (zonas urbana e rural) disponibilizavam exames de rastreamento do câncer do colo do útero, por demanda programada (semanal ou quinzenal), geralmente em dois turnos, sendo que a oferta, na zona rural, era preferencialmente feita pela manhã. Especificamente na zona rural, o exame era ofertado, também, em "unidades satélites" (em microáreas específicas) para facilitar o acesso de populações dispersas, em intervalos de, aproximadamente, quatro meses por localidade. Ademais, destacaram-se as táticas dos enfermeiros que se deslocavam às microáreas e, mesmo em condições muito desfavoráveis (infraestrutura precária), realizavam o citopatológico na residência de moradores que cediam cômodos para tal finalidade assistencial. 
Quadro 2

Composição dos grupos focais.

\begin{tabular}{|c|c|c|c|c|c|}
\hline Municípios & $\begin{array}{l}\text { Número de } \\
\text { grupos }\end{array}$ & $\begin{array}{c}\text { Identificação do } \\
\text { Grupo }\end{array}$ & $\begin{array}{c}\text { Composição dos } \\
\text { grupos }\end{array}$ & $\begin{array}{c}\text { Localidade dos } \\
\text { participante }\end{array}$ & Tempo \\
\hline \multirow[t]{2}{*}{ Maetinga } & \multirow[t]{2}{*}{02} & Grupo I & 10 ACS & Zona urbana e zona rural & $2 \mathrm{~h} 35 \mathrm{~min}$ \\
\hline & & Grupo II & 5 enfermeiros & Zona urbana e zona rural & 2h15min \\
\hline \multirow[t]{2}{*}{ Barra do Choça } & \multirow[t]{2}{*}{02} & Grupo III & 6 ACS & Zona urbana e zona rural & 2h30min \\
\hline & & Grupo IV & 9 enfermeiros & Zona urbana e zona rural & $2 \mathrm{~h} 10 \mathrm{~min}$ \\
\hline \multirow[t]{2}{*}{ Poções } & \multirow[t]{2}{*}{02} & Grupo V & $7 \mathrm{ACS}$ & Zona urbana e zona rural & $2 \mathrm{~h} 35 \mathrm{~min}$ \\
\hline & & Grupo VI & 6 enfermeiros & Zona urbana e zona rural & $1 \mathrm{~h} 35 \mathrm{~min}$ \\
\hline \multirow[t]{4}{*}{ Vitória da Conquista } & \multirow[t]{4}{*}{04} & Grupo VII & 8 ACS & Zona urbana & $2 \mathrm{~h}$ \\
\hline & & Grupo VIII & 6 ACS & Zona urbana e zona rural & $2 \mathrm{~h}$ \\
\hline & & Grupo IX & 6 enfermeiros & Zona urbana & 2h15min \\
\hline & & Grupo X & 7 enfermeiros & Zona urbana e zona rural & $2 \mathrm{~h} 15 \mathrm{~min}$ \\
\hline
\end{tabular}

ACS: agentes comunitários de saúde.

O deslocamento das mulheres da zona rural ao exame de Papanicolaou, segundo ACS e enfermeiros, foi uma das maiores barreiras de acesso na região, uma vez que não havia transporte público regular e/ou as usuárias não dispunham de recursos financeiros para pagamento de condução à USF. Não obstante, as mulheres deslocavam-se a pé, utilizavam, frequentemente, o transporte escolar, eventualmente, os carros da secretária de saúde e/ou outros meios de transportes (com ou sem desembolso direto).

Outrossim, residir em zona rural revelou ser uma importante barreira geográfica para acesso ao citopatológico na região e, logo, reforçava as iniquidades. Nessa perspectiva, populações rurais têm maior dificuldade de acesso aos serviços de saúde, mesmo entre os indivíduos com características socioeconômicas semelhantes que residem em áreas urbanas 8,28, repercutindo em maior incidência de doenças sensíveis à APS 29, bem como, maior mortalidade por câncer de colo do útero entre as mulheres residentes em pequenos municípios e áreas remotas 30,31 .

Além disso, o arranjo organizacional impunha às usuárias que conseguiam alcançar as unidades da zona rural longos tempos de espera (mesmo quando agendadas), em decorrência do deslocamento das equipes da sede municipal ao local de atendimento na zona rural. Em muitas circunstâncias havia um mesmo veículo para o deslocamento de diferentes equipes para localidades distintas da zona rural; em outras, o transporte dos profissionais também levava materiais/insumos e atrasava a saída da equipe para a resolução desta ou outras questões administrativas. Não por acaso, o início do atendimento, nas USF, era prejudicado e gerava insatisfação das mulheres e dos próprios profissionais. Do mesmo modo, o encerramento do turno de trabalho era abreviado, pois havia a necessidade de retorno à sede.

Nesse contexto, o tempo de atendimento na zona rural, de acordo com enfermeiros e ACS, ficava condensado, por conseguinte, havia necessidade de agendamento de um número menor de usuárias, e ainda os citopatológicos eram concentrados num único turno. Até porque, as mulheres de áreas mais remotas frequentavam a USF, especialmente, pela manhã, por conta da maior disponibilidade de transporte e, circunstancialmente, em época de férias escolares (por ausência do transporte escolar) ou em período de plantio/colheita (trabalhadoras do campo) havia diminuição na assiduidade às consultas.

De maneira análoga, populações de áreas rurais, de países de renda alta com sistema de saúde universal e porta de entrada via APS, também apresentavam maior incidência de câncer do colo do útero em decorrência de múltiplas barreiras sociais, entre as quais se destacam as dificuldades no transporte entre residência e serviço de saúde, escassez na disponibilidade dos provedores, questões 


\section{Quadro 3}

Dimensão organizacional do acesso segundo enfermeiros e agentes comunitários de saúde (ACS) da região de saúde de Vitória da Conquista, Bahia, 2018.

\begin{tabular}{|c|c|c|}
\hline Tema & Principais resultados & Estratos de falas dos Grupos Focais \\
\hline \multirow{3}{*}{$\begin{array}{l}\text { Tipo de } \\
\text { oferta de } \\
\text { preventivo }\end{array}$} & \multirow{3}{*}{$\begin{array}{l}\text { Demanda programada; } \\
\text { demanda espontânea; } \\
\text { mutirão (sobretudo, no } \\
\quad \text { Outubro Rosa) }\end{array}$} & $\begin{array}{l}\text { "Você tá com todos os pré-requisitos? Se ela fala que tá, eu faço na hora [o preventivo]! Acolho muita } \\
\text { demanda espontânea!" (GF-VI, Enfermeiros). }\end{array}$ \\
\hline & & $\begin{array}{c}\text { “(...) teve o mutirão do Outubro Rosa, mas não teve o material [pra coleta]. Aí, a gente esperou o Novembro } \\
\text { Azul para gente fazer tudo junto. (...). Foi bom, teve bastante mulher. As vagas foram divididas [entre os } \\
\text { ACS]” (GF-VIII, ACS). }\end{array}$ \\
\hline & & $\begin{array}{l}\text { "Então, meu turno é manhã, quarta-feira manhã, na segunda-feira as mulheres vão no SAME e marcam. } \\
\text { Assim, as que chegarem primeiro marcam primeiro. (...) Eu faço a divisão assim, meus agentes comunitários } \\
\text { têm vaga, por exemplo, meu agente tem uma vaga, então aquela mulher que ele vê que tem muito tempo que } \\
\text { fez preventivo, ele marca e tem, também, as vagas do SAME" (GF-IX, Enfermeiros). }\end{array}$ \\
\hline \multirow{4}{*}{$\begin{array}{l}\text { Local da } \\
\text { oferta do } \\
\text { preventivo }\end{array}$} & \multirow{4}{*}{$\begin{array}{l}\text { USF - ZR e ZU; unidades } \\
\text { satélites (microáreas } \\
\text { da ZR); residências na } \\
\quad \text { comunidade. }\end{array}$} & $\begin{array}{l}\text { "A equipe atende em vários pontos (...) a enfermeira leva todo o material [inclusive a cadeira ginecológica] } \\
\text { pra lá [microárea da ZR] e, lá, eles conseguiram uma salazinha e faz o preventivo lá!" (GF-III, ACS). }\end{array}$ \\
\hline & & $\begin{array}{c}\text { “(...) a gente chegava nos pontos de apoio, principalmente, nas pessoas que têm as lideranças na } \\
\text { comunidade; elas sempre reservavam aquele cantinho na casa dela, pra gente realizar o preventivo e, essa } \\
\text { cadeira ginecológica [transportável] foi ótima!" (GF-IV, Enfermeiros). }\end{array}$ \\
\hline & & $\begin{array}{l}\text { "O preventivo ocorre a cada } 3 \text { ou } 4 \text { meses. E é muito ruim, porque falta material, às vezes. (...) Temos } 3 \text { ou } 4 \\
\text { vagas/microárea; aí, cada vez é uma microárea. E como é só na sede, a maioria tem que ser por área, porque } \\
\text { o transporte vem } 6 \text { h da manhã, volta meio-dia. Tem um lugar que atende em um postinho [unidade satélite], } \\
\text { mas o acesso é muito difícil, aí, nem tem muito lá! (...)" (GF-VIII, ACS). }\end{array}$ \\
\hline & & $\begin{array}{l}\text { "E aí, fazendo preventivo numa localidade lá (...) na casa de uma pessoa e a maca móvel [portátil] não coube } \\
\text { no quarto e a gente fez na cama de uma paciente e providenciaram um banquinho, um tamboretezinho } \\
\text { daqueles (...) E eu sentada nesse banquinho, fazendo os preventivos (...) quando essa pessoa ia sair daqui, de } \\
\text { uma localidade distante, mais ou menos ficava } 70 k m \text { de Vitória da Conquista, pra poder fazer um preventivo" } \\
\text { (GF-X, Enfermeiros). }\end{array}$ \\
\hline \multirow{3}{*}{$\begin{array}{l}\text { Frequência } \\
\text { na oferta de } \\
\text { preventivo }\end{array}$} & \multirow{3}{*}{$\begin{array}{l}\text { Semanal/quinzenal; } \\
\text { sazonal (unidades } \\
\text { "satélites" da ZR); } \\
\text { matutino (mais comum } \\
\text { na ZR) e/ou vespertino }\end{array}$} & $\begin{array}{c}\text { "[preventivo na ZR] é sempre pela manhã, porque, à tarde, pode acontecer uma reunião, uma visita } \\
\text { domiciliar (...) Porque o carro é só pela manhã" (GF-I, ACS). }\end{array}$ \\
\hline & & $\begin{array}{l}\text { "O preventivo é o único exame que tem sempre (...) a enfermeira faz toda semana, faz de manhã e à tarde (...) } \\
\text { pra atender todo o público. Quem trabalha de manhã e não pode ir, vai à tarde!" (GF-V, ACS). }\end{array}$ \\
\hline & & $\begin{array}{l}\text { “(...) a enfermeira abre a agenda do mês e fica lá (...) cada equipe faz o preventivo uma vez por semana e um } \\
\text { turno; se a unidade tem duas equipes, aí, são duas vezes por semana (...) Na minha unidade, marca duas } \\
\text { vezes por semana, só pela manhã, o que é dificultoso. Tem mulher que só pode ir à tarde. E, aí, faltam muito, } \\
\text { mas ela [enfermeira] nunca abriu [vaga] pela tarde (....)" (GF-VIII, ACS). }\end{array}$ \\
\hline \multirow{3}{*}{$\begin{array}{l}\text { Forma de } \\
\text { marcação } \\
\text { para exame } \\
\text { preventivo }\end{array}$} & \multirow{3}{*}{$\begin{array}{c}\text { Diretamente pela } \\
\text { mulher na USF (agenda } \\
\text { aberta); pelo ACS } \\
\text { (cotas); por telefone; } \\
\text { oportunística; filas na } \\
\text { USF (marcação em dia } \\
\text { específico) }\end{array}$} & $\begin{array}{l}\text { "(...) quando a mulher vai fazer o planejamento familiar com a enfermeira, ela agenda, no caso que se já tem } \\
\text { um ano de realizado o preventivo" (GF-I, ACS). }\end{array}$ \\
\hline & & $\begin{array}{l}\text { “(...) Cada semana é um ACS. (...) se a enfermeira fizer o preventivo na sede, dá a vaga pra outras cinco ACS, } \\
\text { que ficam na sede. Porque os outros três ACS já têm os dias de preventivo. Só que eu, além de ter esses dias } \\
\text { de preventivo [na microárea], tenho que ter os meus dias na sede, porque tenho pessoas na sede que não } \\
\text { se deslocam para o meu postinho [unidade satélite]. A sede fica mais perto para elas, mas cá [na sede] fico } \\
\text { com poucas vagas, só duas, porque tenho que dividir" (GF-VIII, ACS). }\end{array}$ \\
\hline & & $\begin{array}{l}\text { "Por exemplo, } 3 \text { ACS ficavam com determinado dia, que eram } 15 \text { vagas/dia, cada um ficava com 5. Aí, elas } \\
\text { [usuárias] já sabiam quais eram os dias que eles [ACS] tinham vaga. Aí, eles iam na casa, agendavam e } \\
\text { avisavam. [Outra forma é] no dia da visita, eles [ACS] dão o papelzinho, orientando elas pra irem marcar } \\
\text { na unidade. (...) é livre demanda também. A agenda é aberta quinzenal, então abro para os primeiros } 15 \text { e, } \\
\text { depois, novamente, em meados da metade do mês, abro novamente a agenda" (GF-X, Enfermeiros). }\end{array}$ \\
\hline
\end{tabular}

(continua) 
Quadro 3 (continuação)

\begin{tabular}{|c|c|c|}
\hline Tema & Principais resultados & Estratos de falas dos Grupos Focais \\
\hline \multirow[t]{3}{*}{$\begin{array}{l}\text { Meio de } \\
\text { locomoção }\end{array}$} & \multirow{3}{*}{$\begin{array}{l}\text { Caminhado, transporte } \\
\text { público, transporte } \\
\text { próprio, transporte } \\
\text { escolar (ZR), veículos } \\
\text { particulares ou caronas }\end{array}$} & $\begin{array}{c}\text { "A prefeitura paga o carro pra deslocar os pacientes. Porque é uma região muito longe e tem lugar que são } \\
18 \mathrm{~km} \text { ou mais pra poder chegar até a unidade! A gente consegue atender a demanda, porque as pessoas } \\
\text { que têm mais condições financeiras vão por conta própria, usam o seu transporte ou, às vezes, o ônibus da } \\
\text { escola" (GF-I, ACS). }\end{array}$ \\
\hline & & $\begin{array}{c}\text { "Muitas vão de transporte particular, outras alugam moto (...) ZR, ainda tem um problema! A região A só } \\
\text { tem transporte na quarta, a região B só tem transporte na quinta (...) tem um período que fica complicado } \\
\text { pra comparecer, período de colheita de café e no período de férias escolares. Porque pra o deslocamento à } \\
\text { unidade, se usa muito o transporte escolar" (GF-V, ACS). }\end{array}$ \\
\hline & & $\begin{array}{c}\text { "Tenho dificuldade por ser ZR! As mulheres, pra chegarem no posto, têm mais dificuldade, porque umas } \\
\text { dependem do carro da escola, outras dependem de carona e outras não têm dinheiro pra pagar!" (GF-VI, } \\
\text { Enfermeiros). }\end{array}$ \\
\hline \multirow[t]{2}{*}{$\begin{array}{l}\text { Profissional } \\
\text { que faz o } \\
\text { exame }\end{array}$} & \multirow[t]{2}{*}{$\begin{array}{l}\text { Enfermeiro (todas as } \\
\text { USF); médico (poucas } \\
\text { USF); estagiários/ } \\
\text { Residentes (USF com } \\
\text { estudantes) }\end{array}$} & $\begin{array}{l}\text { "Tem, também, uma professora, ginecologista, que faz mutirão. Só que às vezes, ela não consegue completar } \\
\text { um número de vagas porque tem mulheres que têm vergonha de fazer o exame, porque tem alunos que } \\
\text { acompanham (...) na maioria das unidades, só quem faz é a enfermeira. Infelizmente! O médico não faz o } \\
\text { papel dele que seria, também, do preventivo. (...) Na minha unidade, a médica de antes fazia, aí, era uma } \\
\text { semana a médica e outra semana, o enfermeiro (...) entrou um outro médico que não faz o preventivo. E, aí, a } \\
\text { gente tem só o enfermeiro que faz" (GF-VII, ACS). }\end{array}$ \\
\hline & & $\begin{array}{l}\text { "Porque na minha equipe a médica não colhia. Então, eu [enfermeira] fazia um turno fixo semanal e uma } \\
\text { sexta a cada quinze dias (...) vejo que, ainda, é uma coisa voltada pra enfermagem, que também podia ser } \\
\text { dividida (...) não devia concentrar só no enfermeiro" (GF-IX, Enfermagem). }\end{array}$ \\
\hline \multirow[t]{4}{*}{$\begin{array}{l}\text { Processo de } \\
\text { trabalho do } \\
\text { ACS }\end{array}$} & \multirow{4}{*}{$\begin{array}{l}\text { Identificação das } \\
\text { mulheres com } \\
\text { preventivo atrasado ou } \\
\text { "faltosas" à consulta; } \\
\text { busca ativa; orientação } \\
\text { sobre o preventivo; } \\
\text { marcação do exame } \\
\text { preventivo. }\end{array}$} & $\begin{array}{l}\text { "No exame preventivo, temos esse vínculo com o ACS, de estar no dia a dia, nas casas dos pacientes. } \\
\text { Então, muitos já pedem pra que elas marquem, que elas vão à unidade pra marcar o preventivo" (GF-II, } \\
\text { Enfermeiros). }\end{array}$ \\
\hline & & $\begin{array}{l}\text { "As mulheres querem saber como agendar o preventivo? A primeira porta é o agente de saúde. Na reunião } \\
\text { mensal, a gente já sai com os dias de preventivo. Nas visitas domiciliares, a gente já sabe quem fez, quem não } \\
\text { fez, aí, informamos quais os dias que tá agendado o preventivo (...) A gente marca, passa toda a orientação } \\
\text { do preventivo, o que tem que ser feito (...) se caso tiver algum problema no PSF, algum imprevisto, volto e } \\
\text { aviso à paciente. Alguns casos que pode ter alguma resistência, a gente mesmo marca dia, horário, certinho, e } \\
\text { ainda liga um dia antes pra saber" (GF-I, ACS). }\end{array}$ \\
\hline & & $\begin{array}{l}\text { “(...) a gente vê quem tá precisando, elas chegam pra a gente e falam (...). A gente faz uma lista, aí, de acordo } \\
\qquad \text { com as vagas, a gente vai colocando (...)” (GF-III, ACS). }\end{array}$ \\
\hline & & $\begin{array}{l}\text { "A gente tem o livro do preventivo. Por exemplo, uma [mulher] passou pela enfermeira; aí, daqui seis meses } \\
\text { tem que voltar. Se ela não comparecer em seis meses, a gente vai atrás. [...] Eu sei quem foi e quem não foi. } \\
\text { Quem não foi, pergunto o porquê" (GF-VII, ACS). }\end{array}$ \\
\hline
\end{tabular}

(continua)

étnicas e baixo nível educacional das mulheres 32,33. Assim sendo, a miríade de problemas incidentes em populações rurais requer que a provisão de cuidados para a superação de mortes evitáveis tenha caráter intersetorial e, por sua vez, os gastos em APS precisam ser alargados para superar o modelo fragmentado e seletivo 22,34.

Outro tipo de acesso ao Papanicolaou, em todas as USF, consoante com ACS e enfermeiros, acontecia por rastreamento oportunístico, ou seja, quando as mulheres procuravam o serviço de saúde por alguma outra razão. Na região de saúde, o rastreamento oportunístico era a ocasião para que os profissionais captassem as usuárias que não buscavam regularmente o serviço, sobretudo, aquelas que residiam em áreas sem ACS, as mulheres que relutavam em agendar ou tinham histórico de ausências às consultas programadas. Outrossim, esse é o padrão predominante no Brasil que, por sua vez, tem como efeito colateral o surgimento de dois grupos destoantes para o diagnóstico precoce: um contin- 


\begin{tabular}{|c|c|c|}
\hline Tema & Principais resultados & Estratos de falas dos Grupos Focais \\
\hline \multirow{5}{*}{$\begin{array}{l}\text { Infraestru- } \\
\text { tura e insu- } \\
\text { mos para } \\
\text { coleta } \\
\text { de } \\
\text { preventivo }\end{array}$} & \multirow{5}{*}{$\begin{array}{l}\text { Salas sem banheiro; } \\
\text { salas inadequadas } \\
\text { para o procedimento } \\
\text { (pequena, sem } \\
\text { climatização); falta de } \\
\text { material necessário } \\
\text { à coleta e para } \\
\text { armazenamento das } \\
\text { lâminas; equipamentos } \\
\text { quebrados (maca ou } \\
\text { foco) }\end{array}$} & $\begin{array}{c}\text { "(...) às vezes falta o espéculo, por exemplo, tem o maior, o menor (...) Às vezes, acontece, principalmente, no } \\
\text { início do ano, pela questão de licitação, falta um ou outro, mas, nessa questão do preventivo, acho que é o } \\
\text { que menos falta” (GF-I, ACS). }\end{array}$ \\
\hline & & $\begin{array}{c}\text { "Na sala que a enfermeira atende, não dá pra fazer o preventivo! Então, é feito no dia que o médico não tem } \\
\text { o atendimento, aí, pega a maca, leva para a sala do médico, pra ter atendimento naquele dia (...) pra fazer } \\
\text { o preventivo (...) Há uns dois anos faltou espéculo do pequeno. Aí, a enfermeira usou o grande. Aí, andou } \\
\text { machucando as mulheres. Aí, elas [usuárias] andaram reclamando" (GF-V, ACS). }\end{array}$ \\
\hline & & $\begin{array}{c}\text { “(...) não tava tendo o material; a quantidade, mas foi uma questão de burocrática, de licitação (...) E, } \\
\text { tínhamos, também, só que o } G \text { [espéculo]! Eu não faço o preventivo com o [espéculo] G, a menos que a } \\
\text { mulher me cobre essa demanda do G" (GF-VI, Enfermeiros). }\end{array}$ \\
\hline & & $\begin{array}{l}\text { “Na nossa unidade tem duas equipes e, aí, a outra enfermeira tem que vim pra sala da gente fazer o } \\
\text { preventivo, porque só tem uma maca, com consultório com banheiro (...) Às vezes, não tinha preventivo } \\
\text { porque não tinha quem limpasse a sala! (...) Temos outro agravante que é a questão do banheiro. A nossa } \\
\text { sala que tem [mesa] ginecológica não tem banheiro. Nossa estrutura física é bem precária. Aí a usuária troca } \\
\text { [roupa] atrás do biombo mesmo! (...) do foco eles [profissionais] reclamam muito, às vezes, a bateria não liga } \\
\text { mais. Está meio quebrado" (GF-VIII, ACS). }\end{array}$ \\
\hline & & $\begin{array}{c}\text { "Não pode ligar ventilador e tem dias que está muito quente. (...) tive que pedir uma caixinha de lâmina. Era } \\
\text { a única coisa que não tinha. (...) Tem unidades que não são forradas, que as mulheres não têm privacidade } \\
\text { na consulta. Às vezes, usava abaixador de língua para substituir a espátula. Já faltou álcool, já falou espectro, } \\
\text { escovinha e até impresso. Tem lugares que não tem a porta, já coloquei um biombo para conseguir atender" } \\
\text { (GF-IX, Enfermeiros). }\end{array}$ \\
\hline
\end{tabular}

GF: grupo focal; PSF: Programa Saúde da Família; SAME: Serviço de Arquivo Médico e Estatística; USF: unidades de saúde da família; ZR: zona rural; ZU: zona urbana.

gente de mulheres super-rastreadas - por realizarem o exame em intervalo de um ano ou menos - e outro grupo sem nunca ter realizado tal procedimento ${ }^{9}$. Logo, trata-se de modelo inadequado de recrutamento, especialmente, para mulheres marginalizadas e de áreas rurais, por serem grupos que, tradicionalmente, buscam menos o serviço ou têm menos provedores à disposição 32 .

Ao mesmo tempo, para ACS e enfermeiros, a queixa sintomatológica foi uma razão recorrente para a busca do preventivo como demanda espontânea. Entretanto, situações que provocam desconforto ginecológico (prurido, leucorreia, metrorragia, dentre outras) são contraindicações para a coleta do Papanicolaou, ou seja, nestas situações, as mulheres necessitariam ser tratadas para retorno programado ao citopatológico. Tal mecanismo, por sua vez, representava um ponto importante para o acesso oportuno e vinculação das usuárias e, deste modo, dirimia barreiras técnicas e simbólicas. No primeiro caso, ao acolher uma demanda real das mulheres e, também, realizar diagnóstico e tratamento, os profissionais resolviam um problema concreto, promoviam uma resposta positiva que repercutia na credibilidade e aceitabilidade do serviço. No segundo caso, as mulheres tinham sua demanda atendida e garantiam uma vaga de retorno para consulta dirigida ao exame citológico, incidindo na adesão ao rastreamento. Segundo ACS e enfermeiros, uma estratégia utilizada em algumas USF, sobretudo aquelas com grande procura, foi a reserva de turno específico para demandas ginecológicas por manifestações sintomáticas e, assim, diminuíram as intercorrências durante o Papanicolaou.

Nada obstante, a busca pelo citopatológico a partir de uma queixa sintomatológica pode revelar o desconhecimento das mulheres quanto à finalidade do Papanicolaou, bem como, sugere que o motivador seja a consulta ginecológica dissociada do caráter preventivo do rastreamento. Nesse sentido, ainda que oportunístico, a realização da assistência ginecológica com exame citopatológico deve ser bem organizada a fim de estender sua abrangência ao conjunto das mulheres, independentemente de sua situação clínica, maternal ou conjugal 12,15,35. 


\section{Quadro 4}

Dimensões simbólica e técnica do acesso, segundo enfermeiros e agentes comunitários de saúde (ACS) da região de saúde de Vitória da Conquista, Bahia, 2018.

\begin{tabular}{|c|c|c|}
\hline Tema & Principais resultados & Estratos de falas dos Grupos Focais \\
\hline \multirow{5}{*}{$\begin{array}{l}\text { Mulheres com } \\
\text { deficiência }\end{array}$} & \multirow{5}{*}{$\begin{array}{c}\text { Barreiras arquitetônicas; } \\
\text { Limitações físicas } \\
\text { das mulheres; } \\
\text { Estereótipo familiar; } \\
\text { Desconhecimento } \\
\text { das necessidades das } \\
\text { mulheres com deficiência; } \\
\text { Barreira comunicacional }\end{array}$} & $\begin{array}{l}\text { "(...) tem muito paciente com transtorno mental e a gente tem essa dificuldade de chamar pra } \\
\text { fazer preventivo. Então, muitas delas ficam sem fazer, porque tem umas que é transtorno bem } \\
\text { avançado, que não dá pra fazer!" (GF-II, Enfermeiros). }\end{array}$ \\
\hline & & $\begin{array}{l}\text { "As minhas [mulheres] vêm carregadas pelos familiares! Porque, já na porta de entrada, não } \\
\text { existe esse acesso! Não tem porque é alta [a calçada]. Aí, já vêm, geralmente, carregadas, a gente } \\
\text { recebe na cadeira de rodas e chega na minha sala. E a gente faz o que consegue fazer" (GF-VI, } \\
\text { Enfermeiros). }\end{array}$ \\
\hline & & $\begin{array}{c}\text { "Às vezes, a própria família embarreira, porque não quer apresentar o deficiente na unidade de } \\
\text { saúde. (...) Eu percebo que, em parte, é a família que não gosta de expor aquela pessoa, pelo fato } \\
\text { da sua deficiência!" (GF-III, ACS). }\end{array}$ \\
\hline & & $\begin{array}{l}\text { "Elas não fazem! (...) Elas queixam a questão da maca. Que não tem uma maca apropriada e que } \\
\text { a posição da maca é inadequada. Essa paciente minha cadeirante é obesa. Cadeirante e obesa! E } \\
\text { para a maca a posição não vai visualizar fundo de útero. Aí, normalmente não faz. (...) [mulheres } \\
\text { com deficiência visual] a gente vê mais, geralmente vão acompanhadas (...) Nossa dificuldade em } \\
\text { relação aos deficientes auditivos é a questão da comunicação" (GF-VIII, ACS). }\end{array}$ \\
\hline & & $\begin{array}{c}\text { "A maior dificuldade que tive foi no início. Até para subir numa maca. Aí, tive que pegar no colo e } \\
\text { colocar, porque não veio ninguém para acompanhar e para descer, ela pulou da maca! (...) Elas } \\
\text { conseguem ter acesso (...) Agora, as acamadas, nunca vi! (...) Tinha uma que me comunicava por } \\
\text { bilhete" (GF-IX, Enfermeiros). }\end{array}$ \\
\hline \multirow[b]{4}{*}{$\begin{array}{l}\text { Orientação sexual das } \\
\text { usuárias }\end{array}$} & \multirow{4}{*}{$\begin{array}{c}\text { Invisibilidade da } \\
\text { homossexualidade } \\
\text { feminina; Estigma; } \\
\text { Tabus; Resistência das } \\
\text { mulheres lésbicas; } \\
\text { Subrastreamento do } \\
\text { câncer de colo de útero }\end{array}$} & $\begin{array}{l}\text { "Quando você conhece a população, acaba indo no automático! A nossa realidade, de cidade } \\
\text { pequena, todo mundo conhece todo mundo (...) talvez essa pessoa tenha até iniciado [outra } \\
\text { orientação sexual], mas tem receio de chegar e contar pra gente" (GF-II, Enfermeiros). }\end{array}$ \\
\hline & & $\begin{array}{l}\text { "Uma pergunta que não vou saber Ihe responder, porque nunca chegou mulheres gays pra mim! } \\
\text { Nunca chegou!" (GF-IV, Enfermeiros). }\end{array}$ \\
\hline & & $\begin{array}{l}\text { “(...) mulher lésbica, tem bastante. Muitas vão, inclusive, com as esposas! Vão e, geralmente, } \\
\text { marcam as duas, no mesmo dia e vão as duas! (...) Tem umas, assim, que têm uma certa } \\
\text { resistência; acham que não têm necessidade, que não precisam, pela orientação sexual (...)” (GF- } \\
\text { VI, Enfermeiros). }\end{array}$ \\
\hline & & $\begin{array}{l}\text { “O pessoal homossexual não se identifica na unidade (...). Não procuram tanto a unidade como } \\
\text { deveriam (...). Deste tempo todo, pouquíssimas vezes, umas três ou quatro vezes que teve. Mas } \\
\text { não tem essa frequência. Eu acho que, para elas mesmas, elas acham que, por ter relação com } \\
\text { outra mulher, não têm risco. (...) Eu tenho uma ACS que é [lésbica], ela tem um relacionamento, é } \\
\text { casada, tem a companheira dela. Mas ela tem uma resistência para fazer [preventivo], até para } \\
\text { falar nesse assunto, entendeu? Então, elas acreditam que não [precisam], principalmente a que } \\
\text { tem um comportamento mais masculino. Aí, a parceira que tem um comportamento feminino, } \\
\text { ela já se cuida mais nessa perspectiva [faz o preventivo]; a outra não (...). Teve uma vez que ela } \\
\text { falou: - 'achava que não precisava fazer, porque nunca tive relação com homem'. Tem algumas } \\
\text { que já tiveram experiência hétero e que, agora, estão em um relacionamento homoafetivo, mas } \\
\text { assim essas: - 'ah, não achei que precisava fazer, porque nunca tive relação com homem. Eu só } \\
\text { tive relação com mulheres” (GF-IX, Enfermeiros). }\end{array}$ \\
\hline
\end{tabular}

(continua) 
Quadro 4 (continuação)

\begin{tabular}{|c|c|c|}
\hline Tema & Principais resultados & Estratos de falas dos Grupos Focais \\
\hline \multirow{5}{*}{ Acolhimento e vínculo } & \multirow{5}{*}{$\begin{array}{l}\text { Cuidado inespecífico; } \\
\text { Culpabilização } \\
\text { das mulheres; } \\
\text { Cuidado singular; } \\
\text { Responsabilização; } \\
\text { Profissional contornando } \\
\text { as barreiras para cuidar }\end{array}$} & $\begin{array}{c}\text { "Tenho uma que é deficiente física e outra, é mental. Mas elas não fazem porque elas não querem } \\
\text { (...) Se fosse pra fazer, essa mental mesmo podia fazer, só que ela fala que não precisa" (GF-I, } \\
\text { ACS). }\end{array}$ \\
\hline & & $\begin{array}{c}\text { "Tem outras [com deficiência] que vêm e vou lá e colho com aquela delicadeza e rápido; pra ela } \\
\text { não se sentir constrangida" (GF-IV, Enfermeiros). }\end{array}$ \\
\hline & & $\begin{array}{l}\text { "Teve um caso que o ACS pegou o carro dele e me levou até à casa dela [usuária]! Ela é totalmente } \\
\text { acamada, tem } 40 \text { e poucos anos e nunca colheu o preventivo. Fui num dia de preventivo, fui lá na } \\
\text { casa dela, levei o foco, fui e colhi o preventivo, lá na casa dela mesmo!" (GF-VI, Enfermeiros). }\end{array}$ \\
\hline & & $\begin{array}{l}\text { "Não tem um tratamento especial para o homossexual. A gente vai acolher de acordo a } \\
\text { necessidade dele. (...) A população mais presente não é a população trans ou homoafetiva, } \\
\text { ela não vem muito (...). Essa se identificou, porque falou: - 'estou tensa!'. Aí: - 'Por quê?'. Tentei } \\
\text { acalmá-la. Ela falou: - 'porque sou homossexual'. E ela tinha essa postura masculina: 'não recebo } \\
\text { a penetração'. Aí, fui acalmar, falei que sou profissional, que não tem isso, e foi tranquilo. Ela } \\
\text { ficou tão à vontade que falou: 'ah, agora quero marcar da minha parceira'. Aí marcou e } 15 \text { dias } \\
\text { depois a parceira dela veio" (GF-IX, Enfermeiros). }\end{array}$ \\
\hline & & $\begin{array}{l}\text { "Na minha área, tenho dificuldade com essas mulheres porque tem uma que tem problema } \\
\text { mental e nunca tinha feito. Graças a Deus, conversei com a mãe dela e pedi para levar ela para } \\
\text { fazer o preventivo. Ela disse que a filha ia dar trabalho, mas tentou e fez" (GF-VII, ACS). }\end{array}$ \\
\hline \multirow{5}{*}{$\begin{array}{l}\text { Valores pessoais e } \\
\text { sociais }\end{array}$} & \multirow{5}{*}{$\begin{array}{l}\text { Submissão ao } \\
\text { companheiro; Machismo; } \\
\text { Tabus; Estigma; } \\
\text { Dificuldade na ZR; Gênero } \\
\text { do profissional }\end{array}$} & $\begin{array}{l}\text { "Elas falam: - 'quando era o enfermeiro fulano e ciclano, eu não vinha, porque tinha vergonha, } \\
\text { por ser homem. E quando tenho corrimento, alguma dor no pé da barriga, fico com vergonha de } \\
\text { passar pelo médico, aí, eu venho pra passar por você'. Elas se sentem mais à vontade, quando é } \\
\text { mulher (...). Elas tinham vergonha de algumas enfermeiras, quando era amiga, ou conhecida (...) } \\
\text { Preferência, né, por não conhecer" (GF-II, Enfermeiros). }\end{array}$ \\
\hline & & $\begin{array}{l}\text { "O pessoal de zona rural, ainda tem aqueles tabus e a gente respeita, não vai chegar e dizer 'Você } \\
\text { vai, tem que ir!' (...) Tem casos que os maridos têm resistência [não permitem que as mulheres } \\
\text { façam o preventivo]. Tem essa cultura de muita gente dizer o seguinte: - 'Eu não tenho relação, } \\
\text { não preciso fazer o preventivo!', [ou ainda]: - 'Eu não tenho parceiro, não vou fazer!"' (GF-V, ACS). }\end{array}$ \\
\hline & & $\begin{array}{l}\text { "Tem algumas mulheres, pelo fato de não tá tendo relação sexual, acham desnecessário... ou pela } \\
\text { idade, acham desnecessário. A gente sempre faz esse trabalho de conscientização! Algumas têm } \\
\text { uma certa resistência, tem uns casos lá que realmente precisa (...) E, elas [profissionais do sexo] } \\
\text { têm uma certa resistência em ir pra unidade!" (GF-VI, Enfermagem). }\end{array}$ \\
\hline & & $\begin{array}{l}\text { "Na área rural, é tudo mais difícil, até os esclarecimentos! E tem mulher que embarreira, que } \\
\text { cria um bloqueio e não tem vontade ou iniciativa pra se cuidar! Então, quando não é ela que } \\
\text { embarreira, [às vezes] o marido não deixa!" (GF-III, ACS). }\end{array}$ \\
\hline & & $\begin{array}{l}\text { "Tem outra lá que vive só com o marido. Ela já é idosa e o marido dela é machista. Então, não } \\
\text { tem muito êxito. (...) Tem pessoas de } 50 \text { anos que nunca fizeram um preventivo (...). Às vezes, é } \\
\text { por ciúmes dos maridos (...) Tem um homem na minha área que, se a mulher falar que vai fazer } \\
\text { preventivo, ele vai para o posto e diz: - 'não faz com homem, viu? É só com mulher'. Agora mesmo } \\
\text { [ela] está sem fazer, porque são dois homens [enfermeiro e médico] e um [médico] não faz [o } \\
\text { exame]. (...) muitas delas por serem uma pessoa de idade, às vezes não tem nem marido e é uma } \\
\text { pessoa sossegada [não faz sexo], acham que não tem marido não precisa fazer (...) às vezes, a } \\
\text { gente vai conversar com uma menina de } 25 / 30 \text { anos e ela diz: - 'Minha mãe morreu com } 70 \text { anos } \\
\text { e nunca fez, pra que eu vou fazer?'. Aí tem que explicar que os tempos mudam, o acesso e tudo. } \\
\text { Tem umas que a gente consegue convencer, tem outras que não" (GF-VII, ACS). }\end{array}$ \\
\hline
\end{tabular}

(continua) 
Quadro 4 (continuação)

\begin{tabular}{|c|c|c|}
\hline Tema & Principais resultados & Estratos de falas dos Grupos Focais \\
\hline \multirow{4}{*}{ Competência técnica } & \multirow{4}{*}{$\begin{array}{l}\text { Aceitabilidade das } \\
\text { mulheres; Adscrição } \\
\text { compulsória; } \\
\text { Preferência por } \\
\text { enfermeiras; Formação } \\
\text { profissional insuficiente; } \\
\text { Desinteresse dos } \\
\text { médicos; Aprendizado na } \\
\text { prática }\end{array}$} & $\begin{array}{l}\text { “(...) pelo fato da enfermeira ser nova, aí fala: - 'Ah! Não vou lá não, uma menina novinha', tem } \\
\text { muito disso, também! (...) E tivemos um período que teve muita resistência pra fazer o preventivo. } \\
\text { De uma pessoa ir na unidade, fazer o preventivo e não gostar (...) Às vezes, não gostar da } \\
\text { enfermeira e sair aquele boato: - 'Não gostei, não gostei, não gostei', e, aí, perde a credibilidade. } \\
\text { Nós, mesmos, tivemos um período que teve muita dificuldade delas irem até a unidade. E, aí, } \\
\text { teve uma enfermeira que conquistou da adolescente à idosa! (...) teve uma época que ficou lá um } \\
\text { enfermeiro, um jovem, e muitas mulheres, principalmente, da terceira idade, ninguém foi fazer o } \\
\text { preventivo! Resistia em fazer com ele, porque ele era um jovem" (GF-V, ACS). }\end{array}$ \\
\hline & & $\begin{array}{l}\text { "Elas falam que a consulta com o enfermeiro é bem melhor do que com ginecologista (...) Pra tirar } \\
\text { dúvida, porque é tudo muito rápido no momento da consulta [com médico] Muitas pacientes da } \\
\text { minha área, quando falei que ia ter que ser com a médica [por conta de liminar], elas diziam } \\
\text { que preferiam esperar pra resolver a situação, ou ia fazer o sacrifício de pagar no privado, mas } \\
\text { não queria fazer com o profissional da unidade! Por que na minha unidade, elas preferem, pois } \\
\text { sentem mais abertura de conversar com o enfermeiro!" (GF-VI, Enfermeiros). }\end{array}$ \\
\hline & & $\begin{array}{c}\text { "Elas gostam mais da enfermeira do que do médico. Falavam que a enfermeira conversa mais, } \\
\text { que a enfermeira é mais carinhosa, sabia colher melhor, que a médica era bruta. (...) Só que } \\
\text { o ano passado teve um negócio de que [somente] a médica que ia colher. Tanto que foi uma } \\
\text { ginecologista lá pra o posto para poder orientar a médica. Mas graças a Deus que voltou tudo ao } \\
\text { normal e é nossa enfermeira que colhe" (GF-VIII, ACS). }\end{array}$ \\
\hline & & $\begin{array}{l}\text { “A gente abriu uma vez [pra médico realizar preventivo], só que aí, assim, enquanto eu fazia } \\
\text { 15, ela fazia metade (...) Aí, a gente viu que, às vezes, era mais proveitoso ela fazer outros tipos } \\
\text { de atendimento do que o preventivo. Porque ela não tinha muita prática, nunca tinha feito (...) } \\
\text { Mas eles [médicos] também encaram como função de especialidade, tipo não é do clínico, não } \\
\text { pertence à atribuição do clínico colher o preventivo e sim do ginecologista. Passei por isso quando } \\
\text { teve o decreto [liminar], que aí a gente ficou um tempo sem colher. Ele [médico] não fez porque: } \\
\text { - 'tem que ir ao ginecologista" (GF-X, Enfermeiros). }\end{array}$ \\
\hline
\end{tabular}

GF: grupo focal; ZR: zona rural.

\section{- Temas: profissional que faz o exame, processo de trabalho do ACS, infraestrutura e insumos para a coleta de preventivo}

Uma questão emblemática foi que, apesar da "competência" técnica, conforme enfermeiros e ACS, raramente o Papanicolaou era realizado por médico. No sentido inverso, foi consenso entre os participantes dos GF que enfermeiros de todas as USF eram a principal referência para a realização do exame citológico e seguimento da usuária, em caso de diagnóstico de alguma alteração. Assim, o protagonismo da enfermagem era um importante marcador de qualidade na organização do rastreamento, visto que, nas USF, tratava-se do profissional mais atuante na linha de cuidado de saúde da mulher. Não por acaso, a enfermagem tem um emergente papel assistencial em diferentes sistemas de saúde 36,37.

Do mesmo modo, para os entrevistados, os ACS desenvolviam um trabalho essencial de identificação e encaminhamento de mulheres ao Papanicolaou, realização de busca ativa de usuárias faltosas ou que apresentavam alteração no exame citopatológico e, frequentemente, seu aprazamento. Por conseguinte, na região de saúde, os ACS tinham centralidade na linha de cuidado de controle do câncer do colo do útero por desenvolver ações orientadas à comunidade e minimizarem as barreiras de acesso. Ainda assim, mesmo ao destacarem o trabalho do ACS como agenciador do cuidado, sobretudo pelo reconhecimento da comunidade, identidade cultural e vínculo social - aspectos imprescindíveis, por exemplo, ao cuidado contínuo e à adesão ao rastreamento do câncer do colo do útero -, diferentes estudos 38 ressaltam, também, as vicissitudes que comprometem a vigilância territorial e a implicação com o processo de trabalho, sobretudo em áreas rurais e com populações vulneráveis 39. 
Ademais, a ausência de itens necessários à coleta de material citopatológico, via de regra, de acordo com os GF, foi uma barreira de acesso em todas as USF. Os profissionais expuseram que, em algumas circunstâncias, houve necessidade de suspensão da coleta do citopatológico, pois faltava material básico (luvas, espéculo descartável, fixador de lâminas, dentre outros) ou, ainda, adaptação do material, como, por exemplo, o uso de espéculo de tamanho inapropriado à anatomia da usuária. Nesse sentido, a privação de instrumentos/insumos, segundo os enfermeiros, esteve relacionada ao atraso no processo licitatório de compras anuais, revelando problemas administrativos que comprometiam o cuidado oportuno/seguro e corroboravam o descrédito no serviço público, com consequente construção de mais uma barreira ao rastreamento do câncer do colo do útero.

A despeito de o cenário regional ser preocupante, um estudo censitário 19 das unidades de saúde de todo Brasil revelou que somente metade dos estabelecimentos de APS apresentava estrutura apropriada para a realização do Papanicolaou, e apenas 30\% das equipes poderiam ser classificadas com prática adequada ao rastreamento. Destarte, uma pesquisa em diferentes regiões de saúde, na Bahia, constatou o provimento irregular de insumo e inadequação da infraestrutura de muitas unidades de saúde 40, e uma investigação em âmbito nacional indicou carência de equipamentos e insumos que restringiam o escopo de ações e a resolubilidade em, aproximadamente, 95\% das unidades 41.

Tais evidências sinalizam barreiras de acesso e qualidade ao cuidado periódico que impactam, também, na adesão das mulheres ao rastreamento, mesmo quando há cobertura do Papanicolaou. Da mesma maneira, diferentes estudos apontam que carências estruturais (insumos e infraestrutura) atingem a disponibilidade, a acessibilidade, a aceitabilidade e, por conseguinte, tornam-se importantes motivos para a não realização do preventivo em tempo oportuno 17,42.

Todavia, enfermeiros e ACS relataram possuir a lista de mulheres na faixa etária preconizada ao rastreamento citopatológico de suas respectivas áreas para monitoramento, bem como, afirmaram discutir, em reuniões de equipe, os casos prioritários e debater acerca das mulheres sem adesão. Isso posto, a utilização de listas de mulheres revela uma estratégia implicada dos profissionais com a comunidade, especialmente, frente à inexistência de um cadastro universal de base populacional 9 e às adversidades impostas por barreiras organizacionais e vulnerabilidades comuns à América Latina 17.

Ao mesmo tempo, todos os entrevistados denunciaram a coexistência de áreas descobertas por ACS no território de muitas equipes, com adscrição populacional excedente (especialmente na zona urbana de Vitória da Conquista) e vulnerabilidade socioeconômica, tudo em sinergia num mesmo território sanitário que, consequentemente, intensificava as barreiras de acesso ao preventivo. Diante de tais adversidades, os profissionais forjavam táticas organizativas por meio do suporte dos ACS na divulgação da agenda em áreas descobertas, consulta oportunística, inclusive, durante ações do programa Bolsa Família, busca ativa de mulheres e realização de mutirões anualmente, na tentativa de minimizar o impacto das barreiras no acesso ao citopatológico.

Outrossim, a utilização dos serviços de saúde é, também, o resultado da interação entre profissionais e usuários, ou seja, da intersubjetividade 43 que, por conseguinte, requer compreender o lugar do sujeito na produção do cuidado e sua influência nas dimensões organizacional, técnica e simbólica do acesso 5 .

\section{Dimensões simbólica e técnica do acesso: intersubjetividade e a produção do cuidado}

A adesão ao exame cervicouterino está intimamente influenciada por valores culturais e, por conseguinte, pela intersubjetividade no encontro entre profissional/usuária 11,12. Sendo assim, a equipe precisa aliar a competência técnica à sensibilidade no agir em saúde, por meio da escuta qualificada e relação dialógica, para reconhecer vulnerabilidades e produzir o cuidado ${ }^{43}$.

\section{- Temas: mulheres com deficiência, orientação sexual das usuárias, acolhimento e vínculo}

Os entrevistados revelaram entraves com que as mulheres com alguma deficiência (física, auditiva, visual ou mental) se deparavam para o acesso ao preventivo. Outrossim, havia barreiras arquitetônicas que limitavam a mobilidade e comprometiam a técnica profissional, bem como obstáculos atitudinais (estigmas e estereótipos) de familiares e de alguns profissionais. Nesse aspecto, as barreiras atitudinais se constituem como violência simbólica às mulheres 44 , que repercutem em iniquidades, salientando- 
se que pessoas com deficiência estão mais expostas a comorbidades 45 e mulheres com deficiência procuram menos o rastreamento do câncer do colo do útero 46,47.

Na mesma direção, em relação à orientação sexual, os enfermeiros nos grupos focais, de modo geral, não percebiam a existência de mulheres que fazem sexo com mulheres ou, de regra, não as indagavam e/ou as mulheres não verbalizavam sua condição nas consultas. Além disso, quando o serviço era procurado por mulheres lésbicas, os profissionais afirmaram não haver diferença no cuidado, com atendimento fragmentado e descontextualizado da orientação sexual, desde o preenchimento na ficha do Sistema de Informação do Câncer (Siscan) à realização do citopatológico. Tais constatações corroboram estudos que sinalizam maior dificuldade de acesso ao Papanicolaou entre as mulheres das camadas populares, que nunca tiveram sexo com homens ou que possuem atributos/posturas corporais autorreferidos com base em categorias como "masculino" 48,49, e desvantagens no acesso aos cuidados na APS para a população LGBT de áreas rurais 50.

Os relatos trouxeram, também, táticas profissionais de responsabilização com o cuidado e ações acolhedoras que encorajavam mulheres com deficiência e/ou lésbicas a frequentarem rotineiramente as USF. Ainda assim, os inúmeros entraves de acesso ao Papanicolaou expõem a seletividade da APS na região, visto que reproduzem a invisibilidade das mulheres com maior vulnerabilidade social e acentuam as desigualdades. Não por acaso, diferentes estudos têm defendido a premência de investimento numa APS abrangente 34,51 e voltada às pessoas 22, a fim de viabilizar a equidade no acesso 6 .

Por esse ângulo, a proximidade e o conhecimento das necessidades de saúde em razão do contexto econômico e social em que vivem as mulheres permitiria aos profissionais reconhecerem as situações simbólicas que atravessam o território e dificultam o acesso ao Papanicolaou, mesmo quando há disponibilidade do serviço.

\section{- Temas: valores pessoais e sociais das usuárias e competência técnica dos profissionais}

Conforme ACS e enfermeiros, importantes barreiras de acesso ao preventivo estavam relacionadas à percepção de necessidade e desejo pelo cuidado, ao receio que algumas mulheres tinham em realizá-lo por desconhecimento e tabus, imposições misóginas do cônjuge, pudor da exposição do corpo (posição de litotomia) ou, ainda, por conta de idade ou gênero do profissional. Tais achados, por vezes em sinergia, são recorrentes em inúmeros estudos 7,12,32,35 e reafirmam a competência cultural dos profissionais como atributo fulcral, por meio do reconhecimento de diferentes necessidades dos grupos populacionais, suas características étnicas, raciais e culturais, a entender suas representações dos processos saúde-enfermidade.

Nada obstante, segundo ACS e enfermeiros, a objeção de parte das mulheres em serem examinadas por profissionais que residiam na própria comunidade (relação de proximidade) ou em razão do gênero do profissional desafiava a adscrição compulsória, ou seja, o cadastramento da população de determinada área geográfica a uma equipe, sem opção de escolha do profissional que a acompanhará em todos os seus ciclos de vida. Tal perspectiva sobrepõe barreiras comuns às dimensões organizativa, técnica e simbólica do acesso 5, além de expor as linhas de tensão no processo de acolhimento. Em contraposição, em países europeus, com sistemas universais e APS como porta de entrada obrigatória, a inscrição nos serviços é efetuada por iniciativa do cidadão, que desfruta de certa liberdade de escolha - e possibilidade posterior de troca - entre profissionais ou serviços atuantes em determinado espaço geográfico 52 .

Na região, de acordo com os participantes dos GF, a competência técnica também foi decisiva na adesão de mulheres ao rastreamento periódico e, nomeadamente, larga preferência pelo profissional de enfermagem em oposição, muitas vezes, ao exame realizado por médicos. A predileção pela enfermeira esteve relacionada tanto ao gênero quanto à qualidade do cuidado, uma vez que, consoante com ACS e enfermeiros entrevistados, a consulta de enfermagem destacava-se pela escuta qualificada, em contraste à clínica médica, percebida como centrada no procedimento e de vínculo frágil com a comunidade. De modo convergente, diferentes estudos 36,53 ressaltam o trabalho desempenhado por enfermeiros para o sucesso do rastreamento rotineiro do câncer do colo do útero e satisfação das usuárias, com destaque na adesão de mulheres oriundas de contextos desfavorecidos. 
Contraditoriamente, para a realização do Papanicolaou, os enfermeiros entrevistados destacaram não haver formação suficiente durante a graduação (insuficiência de atividades práticas) e, por conseguinte, o processo de aprendizagem acontecia no processo de trabalho - curso de abordagem sindrômica - nem sempre ofertado pelo gestor público. Do mesmo modo, os profissionais revelaram que, nos primeiros exames, sentiam-se inseguros e, consequentemente, produziam uma quantidade atípica de amostras insatisfatórias. Na mesma direção, as orientações que os ACS ofertavam à comunidade sobre a temática do câncer do colo do útero derivavam, preponderantemente, da dinâmica interna de cada equipe. Tais experiências, igualmente, foram relatadas por enfermeiros em outras localidades 54,55 .

Ademais, o êxito do rastreamento do câncer do colo do útero perpassa pela melhora na equidade em saúde 6,14,17,56. Assim sendo, atitudes das usuárias sobre os profissionais e vice-versa (confiança e expectativa) e características das práticas (qualidade técnica e interpessoal) são primordiais à consecução do acesso $3,5,20$ e, por conseguinte, constituem a adequação dos serviços de saúde de prevenção ao câncer do colo do útero.

\section{Considerações finais}

A organização da APS, com destaque às barreiras de acesso ao preventivo do câncer do colo do útero em municípios com baixo Índice de Desenvolvimento Humano Municipal (IDH-M), com populações dispersas e residentes em zonas rurais, mesmo com altas coberturas da ESF, demonstra a necessidade de adaptar a resposta dos serviços à especificidade de cada comunidade. Não obstante, obstáculos organizacionais, simbólicos e técnicos, em sinergia, incidem de maneira mais desfavorável em mulheres do campo e mais vulneráveis, resultando em maiores iniquidades, efeitos sociais adversos e reduzindo ganhos de saúde.

Tais achados sinalizam que as práticas na ESF continuam a reproduzir uma atenção despersonalizada e fragmentada. Nessa perspectiva, a condição marcadora foi um importante artifício para a identificação de pontos nevrálgicos no acesso à ESF e, portanto, evidenciou, em alguma medida, a qualidade no processo de cuidado. Os inúmeros entraves de acesso ao Papanicolaou expuseram a seletividade da ESF na região, visto que reproduzia a invisibilidade das mulheres com maior vulnerabilidade social e acentuava as desigualdades.

Por fim, os resultados indicam a necessidade premente de ampliar os investimentos na ESF diante das fragilidades na infraestrutura e disponibilidade de insumos. Nesse sentido, a modelagem da rede regional não será viável frente à gama de municípios com baixa resolubilidade na APS e, por conseguinte, produtores de demandas por serviços especializados, num círculo vicioso, pois retroalimentam as iniquidades.

Como limite do estudo, destaca-se que os resultados foram produzidos na perspectiva de enfermeiros e ACS, e isto dá uma especificidade aos achados. Por sua vez, na exploração do campo, os enfermeiros eram os principais responsáveis pelo citopatológico (razão de sua escolha), e os ACS acumulavam informações diversificadas acerca das mulheres de suas áreas de atuação, bem como, eram interlocutores estratégicos entre a comunidade e os serviços de saúde. Tais características implicam certa representatividade na organização do acesso, minimizando possível lacuna na diversidade dos participantes entrevistados. 


\section{Colaboradores}

N. F. S. Fernandes contribuiu na coleta, análise e interpretação dos dados; redigiu e organizou o artigo. J. R. Galvão colaborou na análise, revisão crítica e redação do artigo. M. M. A. Assis colaborou na metodologia, análise de dados e revisão crítica relevante do conteúdo intelectual. P. F. Almeida participou da concepção, da análise e revisão do artigo. A. M. Santos coordenou a pesquisa, participou da concepção, da análise e revisou o artigo.

\section{Informações adicionais}

ORCID: Noêmia Fernanda Santos Fernandes (0000-0002-0713-949X); Jôse Ribas Galvão (00000003-4131-1393); Marluce Maria Araújo Assis (0000-0003-0063-6677); Patty Fidelis de Almeida (0000-0003-1676-3574); Adriano Maia dos Santos (0000-0001-9718-1562).

\section{Agradecimentos}

À Fundação de Amparo à Pesquisa do Estado da Bahia (Fapesb).

\section{Referências}

1. Assis MMA, Nascimento MAA, Lima WCMB, Oliveira SS, Franco TB, Jorge MSB, et al. Dimensões teóricas e metodológicas da produção do cuidado em saúde. In: Assis MMA, Levi DL, Nascimento MAA, Franco TB, Jorge MSB, organizadores. Produção do cuidado no programa saúde da família: olhares analisadores em diferentes cenários. Salvador: EDUFBA; 2010. p. 13-38.

2. Franco TB, Andrade CS, Ferreira VSC, organizadores. A produção subjetiva do cuidado: cartografias da Estratégia Saúde da Família. São Paulo: Editora Hucitec; 2009.

3. Sanchez RM, Ciconelli RM. Conceitos de acesso à saúde. Rev Panam Salud Pública 2012; 31:260-8.

4. Travassos C, Castro MSM. Determinantes e desigualdades sociais no acesso e utilização dos serviços de saúde. In: Giovanella L, Escorel S, Lobato LVC, Noronha JC, Carvalho AI, organizadores. Políticas e sistema de saúde no Brasil. 2a Ed. Rio de Janeiro: Editora Fiocruz; 2012. p. 183-206.

5. Assis MMA, Jesus WLA. Acesso aos serviços de saúde: abordagens, conceitos, políticas e modelo de análise. Ciênc Saúde Colet 2012; 17:2865-75.

6. Richard L, Furler J, Densley K, Haggerty J, Russel G, Levesque JF, et al. Equity of access to primary healthcare for vulnerable populations: the IMPACT international online survey of innovations. Int J Equity Health 2016; 15:64.

7. Barreto ML. Desigualdades em saúde: uma perspectiva global. Ciênc Saúde Colet 2017; 22:2097-108.

8. Arruda NM, Maia AG, Alves LC. Desigualdade no acesso à saúde entre as áreas urbanas e rurais do Brasil: uma decomposição de fatores entre 1998 a 2008. Cad Saúde Pública 2018; 34:e00213816.

9. Instituto Nacional de Câncer José Alencar Gomes da Silva. Diretrizes brasileiras para o rastreamento do câncer do colo do útero. $2^{\mathrm{a}} \mathrm{Ed}$. Rio de Janeiro: Instituto Nacional de Câncer José Alencar Gomes da Silva; 2016.

10. World Health Organization. Cancer control: knowledge into action. WHO guide for effective programmes - prevention. Geneva: World Health Organization; 2007.

11. Espinosa de Los Monteros K, Gallo LC. The relevance of fatalism in the study of Latinas' cancer screening behavior: a systematic review of the literature. Int J Behav Med 2011; 18:310-8.

12. Rico AM, Iriart JAB. "Tem mulher, tem preventivo": sentidos das práticas preventivas do câncer do colo do útero entre mulheres de Salvador, Bahia, Brasil. Cad Saúde Pública 2013; 29:1763-73.

13. Vale DBAP, Morais SS, Pimenta AL, Zeferino LC. Avaliação do rastreamento do câncer do colo do útero na Estratégia Saúde da Família no Município de Amparo, São Paulo, Brasil. Cad Saúde Pública 2010; 26:383-90. 
14. Navarro C, Fonseca AJ, Sibajev A, Souza CIA, Araújo DS, Teles DAF, et al. Cobertura do rastreamento do câncer de colo de útero em região de alta incidência. Rev Saúde Pública 2015; 49:17.

15. Albuquerque KM, Frias PG, Andrade CLT, Aquino EML, Menezes G, Szwarcwald CL. Cobertura do teste de Papanicolaou e fatores associados à não-realização: um olhar sobre o Programa de Prevenção do Câncer do Colo do Útero em Pernambuco, Brasil. Cad Saúde Pública 2009; 25 Suppl 2:S301-9.

16. Barcelos MRB, Lima RCD, Tomasi E, Nunes BP, Duro SMS, Facchini LA. Qualidade do rastreamento do câncer de colo uterino no Brasil: avaliação externa do PMAQ. Rev Saúde Pública $2017 ; 51: 67$.

17. Goss PE, Lee BL, Badovinac-Crnjevic T, Strasser-Weippl K, Chavarri-Guerra Y, St Louis J, et al. Planning cancer control in Latin America and the Caribbean. Lancet Oncol 2013; 14:391-436.

18. Brito-Silva K, Bezerra AFB, Chaves LDP, Tanaka OY. Integralidade no cuidado ao câncer do colo do útero: avaliação do acesso. Rev Saúde Pública 2014; 48:240-8.

19. Tomasi E, Oliveira TF, Fernandes PAA, Thumé E, Silveira DS, Siqueira VF, et al. Estrutura e processo de trabalho na prevenção do câncer de colo de útero na Atenção Básica à Saúde no Brasil: Programa de Melhoria do Acesso e da Qualidade - PMAQ. Rev Bras Saúde Mater Infant 2015; 15:171-80.

20. Bottari CMS, Vasconcellos MM, Mendonça MHM. Câncer cérvico-uterino como condição marcadora: uma proposta de avaliação da atenção básica. Cad Saúde Pública 2008; 24 Suppl 1:S111-22.

21. Mendes EV. As redes de atenção à saúde. 2a Ed. Brasília: Organização Pan-Americana da Saúde; 2011.

22. World Health Organization. Primary health care: now more than ever. Geneva: World Health Organization; 2008.

23. Santos AM, Giovanella L, Mendonça MHM, Andrade CLT, Martins MIC, Cunha MS. Práticas assistenciais das Equipes de Saúde da Família em quatro grandes centros urbanos. Ciênc Saúde Colet 2012; 17:2687-702.

24. Minayo MCS. O desafio do conhecimento: pesquisa qualitativa em saúde. 14ạ Ed. São Paulo: Editora Hucitec; 2014.

25. Brasil. Decreto no 7.508 de 28 de junho de 2011. Regulamenta a Lei no 8.080 , de 19 de setembro de 1990, para dispor sobre a organização do Sistema Único de Saúde - SUS, o planejamento da saúde, a assistência à saúde e a articulação interfederativa, e dá outras providências. Diário Oficial da União 2011; 29 jun.

26. Barbour R. Grupos focais. Porto Alegre: Artmed; 2009.

27. Tong A, Sainbury P, Craig J. Consolidated criteria for reporting qualitative research (COREQ): a 32-item checklist for interviews and focus groups. Int J Qual Health Care 2007; 19:349-57.
28. Gomes KO, Reis EA, Guimarães MDC, Cherchiglia ML. Utilização de serviços de saúde por população quilombola do Sudoeste da Bahia, Brasil. Cad Saúde Pública 2013; 29:1829-42.

29. Greer R, Boulware LE. Reducing CKD risks among vulnerable populations in primary care. Adv Chronic Kidney Dis 2015; 22:74-80.

30. Silva GA, Gamarra CJ, Girianelli VR, Valente JG. Tendência da mortalidade por câncer nas capitais e interior do Brasil entre 1980 e 2006. Rev Saúde Pública 2011; 45:1009-18.

31. Sosa-Rubí SG, Walker D, Sérvan E. Práctica de mastografías y pruebas de Papanicolaou entre mujeres de áreas rurales de México. Salud Pública Méx 2009; 51 Suppl 2:S236-45.

32. Maar M, Burchel A, Little J, Ogilvie G, Severini A, Yang JM, et al. A qualitative study of provider perspectives of structural barriers to cervical cancer screening among first nations women. Womens Health Issues 2013; 23:e31925.

33. McLeod M, Harris R, Purdie G, Cormack D, Robson B, Sykes P, et al. Improving survival disparities in cervical cancer between Māori and non-Māori women in New Zealand: a national retrospective cohort study. Aust N Z J Public Health 2010; 34:193-9.

34. Magnussen L, Ehiri J, Jolly P. Comprehensive versus selective pimary health care: lessons for global health policy. Health Affairs 2004; 23:167-76.

35. Ribeiro L, Bastos RR, Vieira MT, Ribeiro LC, Teixeira MTB, Leite ICG. Rastreamento oportunístico versus perdas de oportunidade: não realização do exame de Papanicolaou entre mulheres que frequentaram o pré-natal. Cad Saúde Pública 2016; 32:e00001415.

36. Perks J, Algoso M, Peters K. Nurse practitioner (NP) led care: cervical screening practices and experiences of women attending a women's health centre. Collegian 2017; 25:493-9.

37. Toso BRGO, Filippon J, Giovanella G. Atuação do enfermeiro na Atenção Primária no Serviço Nacional de Saúde da Inglaterra. Rev Bras Enferm 2016; 69:182-91.

38. Alonso CMC, Béguin PD, Duarte FJCM. Trabalho dos agentes comunitários de saúde na Estratégia Saúde da Família: metassíntese. Rev Saúde Pública 2018; 52:14.

39. Lara MO, Brito MJM, Rezende LC. Aspectos culturais das práticas dos agentes comunitários de saúde em áreas rurais. Rev Esc Enferm USP 2012; 46:673-80.

40. Almeida PF, Santos AM. Atenção primária à saúde: coordenadora do cuidado em redes regionalizadas? Rev Saúde Pública 2016; 50:80.

41. Bosquat A, Giovanella L, Fausto MCR, Fusaro ER, Mendonça MHM, Gagno J, et al. Tipologia da estrutura das unidades básicas de saúde brasileiras: os 5 R. Cad Saúde Pública 2017; 33:e00037316. 
42. Correa MS, Silveira DS, Siqueira FV, Facchini LA, Piccini RX, Thumé E, et al. Cobertura e adequação do exame citopatológico de colo uterino em estados das regiões Sul e Nordeste do Brasil. Cad Saúde Pública 2012; 28:225766.

43. Ayres JRCM. Sujeito, intersubjetividade e práticas de saúde. Ciênc Saúde Colet 2001; 6:6372.

44. França ISX, Pagliuca LMF, Baptista RS, França EG, Coura AS, Souza JA. Violência simbólica no acesso das pessoas com deficiência às unidades básicas de saúde. Rev Bras Enferm 2010; 63:964-70.

45. Castro SS, Lefèvre F, Lèvefre AMC, Cesar CLG. Acessibilidade aos serviços de saúde por pessoas com deficiência. Rev Saúde Pública 2011; 45:99-105.

46. Fang WH, Yen CF, Hu J, Lin JD, Loh CH. The utilization and barriers of Pap smear among women with visual impairment. Int J Equity Health 2016; 15:65.

47. Ramjan L, Cotton A, Algoso M, Peters K. Barriers to breast and cervical cancer screening for women with physical disability: a review. Women Health 2016; 56:141-56.

48. Barbosa RM, Facchini R. Acesso a cuidados relativos à saúde sexual entre mulheres que fazem sexo com mulheres em São Paulo, Brasil. Cad Saúde Pública 2009; 25 Suppl 2:S291-300.

49. Tracy JK, Schluterman NH, Greenberg DR. Understanding cervical cancer screening among lesbians: a national survey. BMC Public Health 2013; 13:442.
50. Whitehead J, Shaver J, Stephenson R. Outness, stigma, and primary health care utilization among rural LGBT populations. PLoS One 2016; 11:e0146139.

51. Kringos D, Boerma W, Bourgueil Y, Cartier T, Dedeu T, Hasvold T, et al. The strength of primary care in Europe: an international comparative study. Br J Gen Pract 2013; 63:e742-50.

52. Giovanella L, Mendonça MHM. Atenção primária à saúde. In: Giovanella L, Escorel S, Lobato LVC, Noronha JC, Carvalho AI, organizadores. Políticas e sistema de saúde no Brasil. 2a Ed. Rio de Janeiro: Editora Fiocruz; 2012. p. 493-545.

53. Armstrong N, James V, Dixon-Woods M. The role of primary care professionals in women's experiences of cervical cancer screening: a qualitative study. Fam Pract 2012; 29:462-6.

54. Viana MRP, Moura MEB, Nunes BMVT, Monteiro CFS, Lago EC. Formação do enfermeiro para a prevenção do câncer de colo uterino. Rev Enferm UERJ 2013; 21(Esp1):624-30.

55. Awodele O, Adeyomoye AA, Awodele DF, Kwashi V, Awodele IO, Dolapo DC. A study on cervical cancer screening amongst nurses in Lagos University Teaching Hospital, Lagos, Nigeria. J Cancer Educ 2011; 26:497-504.

56. Grillo F, Vallée J, Chauvin P. Inequalities in cervical cancer screening for women with or without a regular consulting in primary care for gynaecological health, in Paris, France. Prev Med 2012; 54:259-65. 


\section{Abstract}

This article evaluates access to the Papanicolaou test in the Family Health Strategy (FHS) in municipalities in a health region. Cervical cancer control depends on a well-organized Family Health Strategy, so assessment of access to the Papanicolaou test reflects the quality of care at this level. This is a qualitative study with data produced in 10 focus groups, totaling 70 participants in four municipalities. We analyzed the organizational, symbolic, and technical dimensions of access to the Pap test, with cervical cancer control as the marker. The results indicate that living in rural areas was a barrier to access to the Papanicolaou test and exacerbated the inequalities. Nurses were the principal reference for access to the Pap test. The absence of necessary items for collecting cervical cytopathology specimens was a barrier to access in all the municipalities. There were obstacles to access for women with disabilities and lesbian women, with care that was fragmented and out of sync with individual characteristics. The numerous obstacles to access to the Papanicolaou test exposed the selectiveness of the Family Health Strategy in the health region, since it reproduced the invisibility of women with greater social vulnerability and exacerbated the existing inequalities.

Health Services Accessibility; Uterine Cervical Neoplasias; Rural Health; Primary Health Care; Women's Health

\section{Resumen}

Este artículo evalúa el acceso al examen Papanicolaou dentro del programa Estrategia Salud de la Familia (ESF), en municipios de una región de salud. El control del cáncer de cuello uterino depende de una ESF organizada, por lo tanto, evaluar el acceso al test de Papanicolaou revela la calidad de la asistencia en este nivel de atención. Se trata de un estudio cualitativo, con datos producidos dentro de 10 grupos focales, donde estaban incluidos 70 participantes en cuatro municipios. Se analizaron las dimensiones organizativas, simbólicas y técnicas del acceso al examen preventivo, considerándose condición marcadora el cáncer de cuello uterino. Los resultados indicaron que residir en una zona rural era una barrera para el acceso al examen Papanicolaou y reforzaba las inequidades. Los enfermeros eran la principal referencia para la realización del examen preventivo. La ausencia de ítems necesarios para la recogida de material citopatológico fue una barrera de acceso en todos los municipios. Había trabas de acceso a mujeres con alguna deficiencia y a mujeres lesbianas, con atención fragmentada y descontextualizada de las singularidades personales. Las innumerables trabas de acceso al Papanicolaou expusieron la selectividad de la ESF en la región de salud, debido a que reproducía la invisibilidad de las mujeres con mayor vulnerabilidad social y acentuaba desigualdades.

Accesibilidad a los Servicios de Salud; Neoplasms del Cuello Uterino; Salud Rural; Atención

Primaria de Salud; Salud de la Mujer
Recebido em 05/Dez/2018

Versão final reapresentada em 23/Mar/2019

Aprovado em 15/Abr/2019 